\title{
Management of osteoporosis and menopausal symptoms: focus on bazedoxifene/conjugated estrogen combination
}

This article was published in the following Dove Press journal:

International Journal of Women's Health

7 August 2013

Number of times this article has been viewed

\author{
Sebastian Mirkin' \\ James H Pickar ${ }^{2}$ \\ 'Pfizer Inc, Collegeville, PA, \\ ${ }^{2}$ Department of Obstetrics and \\ Gynecology, Columbia University \\ Medical Center, New York, NY, USA
}

Correspondence: Sebastian Mirkin Pfizer Inc, 500 Arcola Rd, Collegeville, PA 19426, USA

$\mathrm{Tel}+\mid 4848654$ | 2 I

Fax + I 4848654321

Email sebastian.mirkin@pfizer.com

\begin{abstract}
Loss of estrogen production in women during menopause results in a state of estrogen deficiency which has been associated with multiple problems, including vasomotor symptoms, symptoms of vulvovaginal atrophy, bone loss, and difficulties with sleep, mood, memory, and sexual activity. The only treatment option currently available to address multiple postmenopausal symptoms in women with an intact uterus is estrogen/progestin-containing hormone therapy (HT). Concerns surrounding side effects and published data regarding the association of HT with the increased risk for breast cancer have induced a decrease in the number of women seeking, initiating, and continuing this type of therapy. A combination containing bazedoxifene and conjugated estrogens (BZA/CE) maintains the established benefits of estrogen therapy for treatment of postmenopausal vasomotor symptoms, vulvovaginal atrophy, and osteoporosis, while certain estrogenic effects, such as stimulation of the uterus and breast, are antagonized without the side effects associated with HT. BZA/CE has been evaluated in a series of multicenter, randomized, double-blind, placebo-controlled, and active-controlled Phase III trials known as the Selective estrogens, Menopause, And Response to Therapy (SMART) trials. BZA/CE demonstrated clinically meaningful improvements in vasomotor symptoms, vulvovaginal atrophy, and a protective effect on the skeleton. These clinical benefits were associated with an acceptable safety profile and an improved tolerability compared with HT. BZA/CE showed a favorable safety profile on the breast, endometrium, and ovaries. The incidence of venous thromboembolism was low and the risk does not appear to be any greater than for CE alone or BZA alone or greater than HT. The incidence of coronary heart disease and cerebrovascular accidents were similar to placebo. The overall incidence of cancer (including breast cancer) was low and similar to placebo. The SMART trials demonstrate that BZA/CE is an alternative option for treating non-hysterectomized, symptomatic, postmenopausal women.
\end{abstract}

Keywords: tissue selective estrogen complex, bazedoxifene, conjugated estrogens, menopause, osteoporosis, vasomotor symptoms

\section{Introduction}

Loss of ovarian estrogen production in women during menopause results in a state of estrogen deficiency ${ }^{1}$ which has been associated with multiple problems, including vasomotor symptoms, symptoms of vulvovaginal atrophy, and difficulties with sleep, mood, memory, and sexual activity. ${ }^{2}$ During menopause, these symptoms commonly overlap, presenting as a continuum, and may have a negative impact on a woman's quality of life. ${ }^{3}$ Menopausal symptoms have also been negatively associated with the ability to work. ${ }^{4}$ Estrogen deficiency has further been associated with loss of bone mass, often leading to osteoporosis, which is associated with an increased occurrence 
of skeletal fractures. ${ }^{2}$ Women who sustain osteoporotic fractures also face a negative impact on their quality of life, often affecting their ability to function and putting them at an increased risk of morbidity and mortality. $2,5,6$

A variety of therapeutic options are available for the individual symptoms associated with menopause. Estrogen/ progestin-containing hormone therapy (HT) is the only currently approved treatment for women with a uterus that holistically addresses the postmenopausal problems of vasomotor symptoms and vulvovaginal atrophy, while maintaining bone mass. ${ }^{3}$

HT has pharmacologic drawbacks, including vaginal bleeding and breast pain/tenderness, which are the most common reasons for discontinuation of this therapy. ${ }^{7-9}$ Vaginal bleeding leads to discontinuation of therapy in up to one-third of women and rates of discontinuation can be as high as $68 \%$ within the first year of treatment. ${ }^{10}$ Rates of discontinuation for breast tenderness/pain have been reported to be as high as $40 \%$ in some clinical trials. ${ }^{11,12}$ Progestin-induced irregular vaginal bleeding associated with $\mathrm{HT}$ creates distress and often requires additional interventions (ie, transvaginal ultrasonography, endometrial biopsies, and hysteroscopies). ${ }^{13}$ Increases in breast density associated with progestin-containing HT may lead to mammographic recalls because of difficulty in reading mammogram results. Mammographic recalls also increase anxiety in women, contributing to the decision to discontinue HT. ${ }^{14,15}$

Women's concerns about the available therapeutic options for postmenopausal symptoms have resulted in a substantial population who are currently untreated. ${ }^{3}$ The population of postmenopausal women will grow, given the continual increase in the numbers of women approaching menopause and the extended life expectancy of postmenopausal women. ${ }^{1}$ Thus, for postmenopausal women with a uterus, new therapeutic alternatives with an improved tolerability and safety profile compared with traditional HT are needed to help alleviate vasomotor symptoms and vulvovaginal atrophy symptoms, and to prevent osteoporosis.

BZA/CE combines bazedoxifene (BZA), a selective estrogen receptor modulator, with conjugated estrogens (CE), and represents a new treatment option in the management of menopausal health for women with a uterus. BZA/CE maintains the established benefits of estrogen therapy for menopausal symptoms of vasomotor symptoms, vulvovaginal atrophy, and prevention of osteoporosis, while preventing the stimulatory estrogenic effects on the uterus and estrogenic/ progestogenic effects on breast tissue.
The rationale for development of BZA/CE was that BZA, acting as an estrogen receptor antagonist in uterine tissue, would inhibit the proliferative effects of estrogen on the endometrium in a manner mechanistically distinct from progestins, and therefore reduce the incidence of irregular uterine bleeding.

BZA acts as an estrogen receptor antagonist in breast tissue, so BZA/CE is posited not to induce breast pain or changes in breast density. BZA/CE does not cause morphologic changes in the mammary gland, and it is hypothesized that this is the pharmacologic explanation for the lack of changes in breast pain and density. In vitro and vivo models demonstrate that BZA also inhibits the proliferative stimulatory action of estrogens on breast cancer cells. ${ }^{16}$

The objective of this review is to present key efficacy and safety findings from the Selective estrogens, Menopause, And Response to Therapy (SMART) trials. ${ }^{17-20}$

\section{Clinical studies with BZA/CE}

$\mathrm{BZA} / \mathrm{CE}$ has been evaluated in a series of multicenter, randomized, double-blind, placebo-controlled, and activecontrolled Phase III investigations known as the SMART trials (Table 1). ${ }^{17-20}$

The SMART- 1 trial $(\mathrm{n}=3,397)$ was conducted at 94 sites in the United States, Europe, and Brazil and enrolled generally healthy, postmenopausal women aged $40-75$ years. ${ }^{17}$ Eligible subjects had to have an intact uterus, a body mass index (BMI) $\leq 32.2 \mathrm{~kg} / \mathrm{m}^{2}$, and normal endometrial biopsy results at screening. SMART-1 evaluated the efficacy of multiple doses of BZA/CE (combinations of BZA $10 \mathrm{mg}$, $20 \mathrm{mg}$, and $40 \mathrm{mg}$ with either CE $0.45 \mathrm{mg}$ or CE $0.625 \mathrm{mg}$ ) with regard to uterine protection, vasomotor symptoms, vulvovaginal atrophy, and prevention of osteoporosis. ${ }^{17}$

The one-year interim results from SMART-1 demonstrated that BZA $20 \mathrm{mg} / \mathrm{CE} 0.45 \mathrm{mg}$ and BZA $20 \mathrm{mg} / \mathrm{CE}$ $0.625 \mathrm{mg}$ have a low $(<1 \%)$ incidence of endometrial hyperplasia, while reducing the number and severity of hot flushes, improving symptoms of vulvovaginal atrophy, and preventing bone loss. Therefore, BZA $20 \mathrm{mg} / \mathrm{CE} 0.45 \mathrm{mg}$ and BZA $20 \mathrm{mg} / \mathrm{CE} 0.625 \mathrm{mg}$ were selected for further evaluation in other SMART trials. ${ }^{17}$

The SMART-2 trial $(\mathrm{n}=318)$ was conducted at 43 sites in the United States and enrolled healthy, postmenopausal women aged 40-65 years with an intact uterus and a BMI $\leq 34.0 \mathrm{~kg} / \mathrm{m}^{2}$. Eligible subjects had to have seven or more moderate to severe hot flushes daily (or at least 50 per week) at screening and be seeking treatment for hot flushes. This study evaluated the effects of BZA $20 \mathrm{mg} / \mathrm{CE} 0.45 \mathrm{mg}$ 


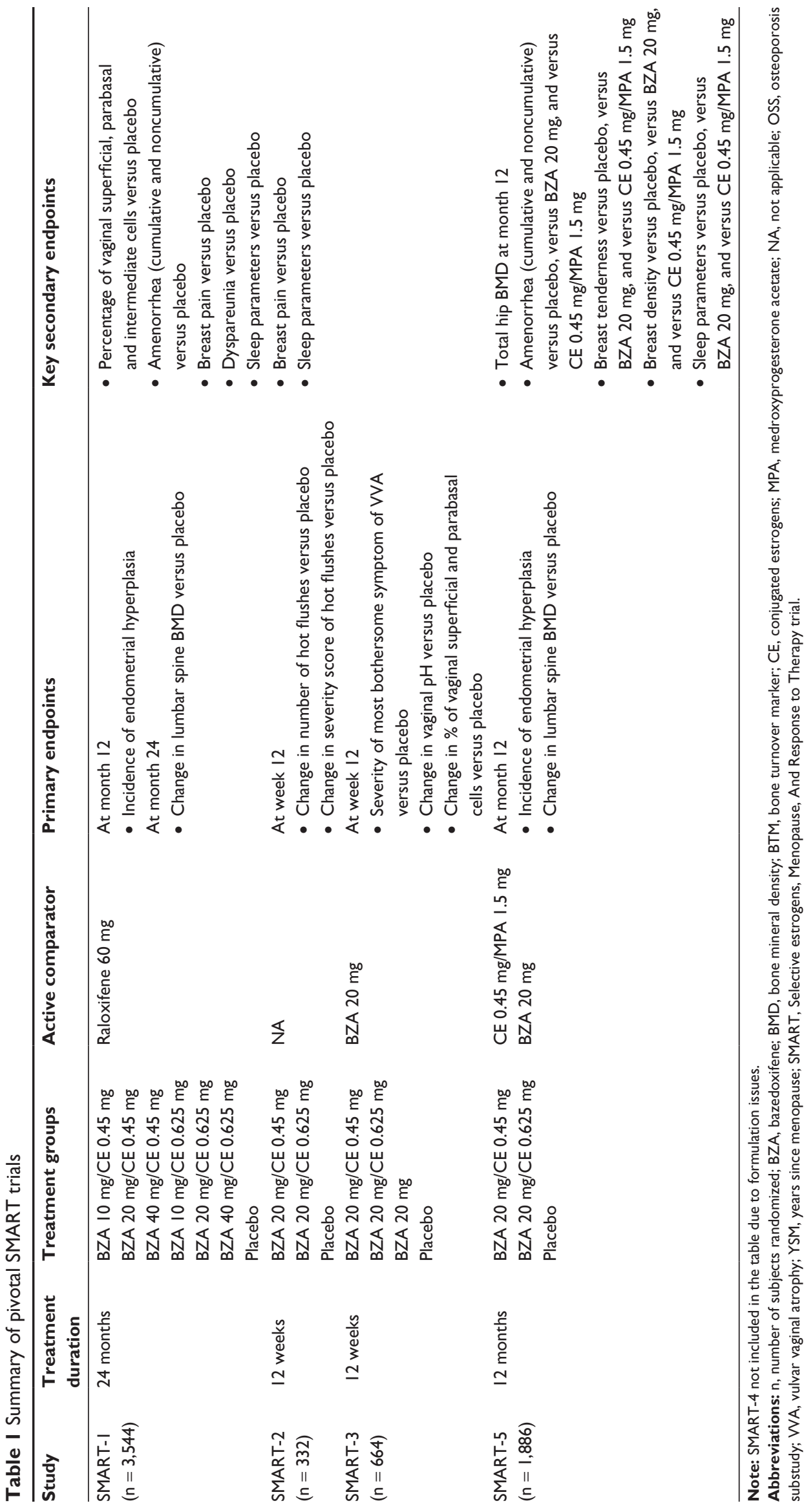


and $0.625 \mathrm{mg}$ on vasomotor symptoms compared with the effects of placebo over 12 weeks of treatment. The primary endpoint was change from baseline in the frequency and severity of hot flushes. Secondary endpoints included effects on sleep, quality of life, and satisfaction with treatment. ${ }^{18}$

The SMART-3 trial $(n=652)$ was conducted at 66 sites in the United States and enrolled generally healthy, postmenopausal women aged 40-65 years with an intact uterus and $\mathrm{a}$ BMI $\leq 34.0 \mathrm{~kg} / \mathrm{m}^{2}$. All women had to have a vaginal cytologic smear showing no more than 5\% superficial cells, a vaginal $\mathrm{pH}>5$, and at least one moderate to severe vulvovaginal atrophy symptom at screening. This study examined the effects of BZA $20 \mathrm{mg} / \mathrm{CE} 0.45 \mathrm{mg}$ and $0.625 \mathrm{mg}$ compared with those of BZA $20 \mathrm{mg}$ alone and placebo on measures of vulvovaginal atrophy over 12 weeks of treatment. ${ }^{19}$

The SMART-5 trial $(n=1,886)$ was conducted at 166 sites in the United States, Europe, Latin America, Australia, and New Zealand, and enrolled generally healthy, postmenopausal women aged 40-75 years. Eligible subjects had to have an intact uterus, a BMI $\leq 34 \mathrm{~kg} / \mathrm{m}^{2}$, and acceptable endometrial biopsy results at screening. SMART-5 evaluated the efficacy of BZA/CE on uterine protection, prevention of osteoporosis, and effect on breast density. ${ }^{20}$ This study evaluated the effects of BZA $20 \mathrm{mg} / \mathrm{CE} 0.45$ and $0.625 \mathrm{mg}$ and included CE/medroxyprogesterone acetate (MPA, (Prempro ${ }^{\circledR}$, Pfizer Pharmaceuticals Inc, New York, NY, USA), BZA, and placebo as comparators.

The results of the one-year SMART-4 study $(n=1,061)$ are not discussed in this review because a different formulation of BZA/CE was evaluated. Regardless, the results of the SMART-4 study were similar to those of the SMART-1 study. ${ }^{17}$

\section{Efficacy on hot flushes, health related-quality of life, and sleep}

Two clinical trials (SMART-1 and SMART-2) evaluated the efficacy of BZA/CE for the treatment of moderate to severe vasomotor symptoms. In these studies, BZA $20 \mathrm{mg} / \mathrm{CE} 0.45 \mathrm{mg}$ and BZA $20 \mathrm{mg} / \mathrm{CE} 0.625$ were associated with clinically meaningful improvements in vasomotor symptoms as compared with placebo, and the efficacy was comparable with that of available hormonal options (HT and estrogen therapy). ${ }^{17,18}$

In SMART-2, at week 4, BZA $20 \mathrm{mg} / \mathrm{CE} 0.45 \mathrm{mg}$ and BZA $20 \mathrm{mg} / \mathrm{CE} 0.625 \mathrm{mg}$ were associated with a significant decrease $(P<0.001)$ in the adjusted mean daily number of moderate to severe hot flushes as compared with placebo. A clinically meaningful reduction of 5-6 hot flushes per day was observed in subjects treated with BZA $20 \mathrm{mg} / \mathrm{CE} 0.45 \mathrm{mg}$ and BZA $20 \mathrm{mg} / \mathrm{CE} 0.625 \mathrm{mg}$, respectively, compared with a reduction of three hot flushes in the placebo group. At week 12, BZA $20 \mathrm{mg} / \mathrm{CE} 0.45 \mathrm{mg}$ and BZA $20 \mathrm{mg} / \mathrm{CE} 0.625 \mathrm{mg}$ were associated with a decrease $(P<0.001)$ in the adjusted mean daily number of moderate to severe hot flushes, reaching a $74 \%$ and a $80 \%$ reduction, respectively, representing a clinically meaningful reduction of approximately 7-8 hot flushes per day, compared with a 51\% reduction (representing a reduction of approximately five hot flushes per day) in the placebo group (Figure 1). ${ }^{18}$

In addition to significant reductions in the number of moderate to severe hot flushes experienced per day, both BZA $20 \mathrm{mg} / \mathrm{CE} 0.45 \mathrm{mg}$ and BZA $20 \mathrm{mg} / \mathrm{CE} 0.625 \mathrm{mg}$ dose strengths demonstrated clinically meaningful reductions in the severity of moderate to severe hot flushes compared with subjects who received placebo at week 4 (26\% and 29\% reduction, respectively) and week 12 (39\% to 55\% reduction, respectively, $P<0.001$, Figure 2). ${ }^{18}$ Similar results were observed in SMART-1, with evidence of efficacy of $\mathrm{BZA} / \mathrm{CE}$ for the treatment of vasomotor symptoms present through 2 years of therapy. ${ }^{17}$

BZA $20 \mathrm{mg} / \mathrm{CE} 0.45 \mathrm{mg}$ and BZA $20 \mathrm{mg} / \mathrm{CE} 0.625$ was associated with clinically meaningful improvements in vasomotor symptoms. Comparison with historical data reveals that both the BZA $20 \mathrm{mg} / \mathrm{CE} 0.45 \mathrm{mg}$ and BZA $20 \mathrm{mg} / \mathrm{CE}$ $0.625 \mathrm{mg}$ dose strengths have an overall comparable efficacy with that of estrogen progestin-containing HT compounds in the relief of moderate to severe hot flushes associated with menopause. ${ }^{21}$

Both BZA $20 \mathrm{mg} / \mathrm{CE} 0.45 \mathrm{mg}$ and BZA $20 \mathrm{mg} / \mathrm{CE}$ $0.625 \mathrm{mg}$ treatment groups demonstrated efficacy for both the daily number and severity of moderate to severe hot flushes, regardless of racial characteristics, BMI, and years since menopause of the populations evaluated. ${ }^{18}$

Health-related quality of life, sleep parameters, and patient satisfaction tools were also used to assess patient response to therapy in the SMART-2 study. Clinically significant improvements were reported with BZA $20 \mathrm{mg} /$ CE 0.45 and $0.625 \mathrm{mg}$ at 12 weeks compared with placebo in the vasomotor function domain of the Menopause-Specific Quality of Life questionnaire and significantly greater satisfaction in the ability to control hot flushes during the day and night according to the Menopause Symptoms Treatment Satisfaction Questionnaire. ${ }^{22}$

A range of components of the Medical Outcomes Study sleep scale also showed significant improvements with BZA/ $\mathrm{CE}$ versus placebo, including significant decreases in sleep disturbance and significant increases in sleep adequacy. ${ }^{22}$ 


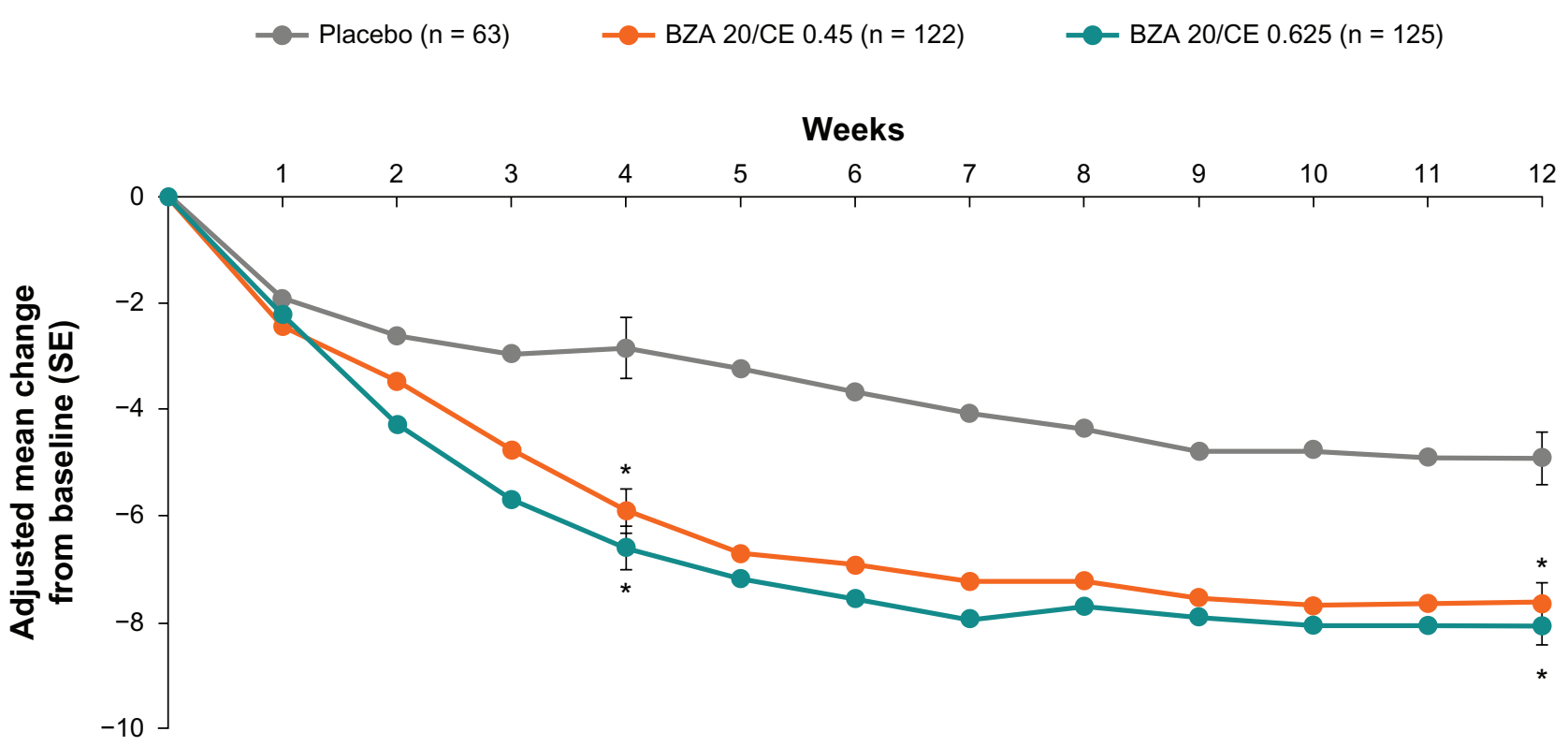

Figure I SMART-2 trial: mean daily number of hot flushes with up to 12 weeks of treatment with BZA/CE or placebo for the MITT population using LOCF. Statistical significance $(P<0.01)$ was achieved for BZA $20 \mathrm{mg} / \mathrm{CE} 0.45 \mathrm{mg}$ during weeks 3 through 12 compared with placebo. At week 2 through I2, the mean daily number of hot flushes with BZA $20 \mathrm{mg} / \mathrm{CE} 0.625 \mathrm{mg}$ was statistically significant $(P<0.0 \mathrm{I})$ from placebo. $* P$-value vs placebo $<0.00 \mathrm{I}$.

Abbreviations: BZA, bazedoxifene; CE, conjugated estrogens; LOCF, last observation carried forward; MITT, modified intent-to-treat; SMART, Selective estrogens, Menopause, And Response to Therapy trial; SE, standard error.

Additionally, BZA/CE improved both indices (sleep problem index 1 and 2) included in the Medical Outcomes Study sleep scale (Figure 3). Statistical mediation modeling demonstrated that BZA/CE affected sleep directly in populations of women with severe vasomotor symptoms, while in less symptomatic women its effect was indirect via improvement in hot flushes. ${ }^{22}$

In summary, BZA/CE was associated with a clinically meaningful reduction in vasomotor symptoms, comparable with that observed for HT; moreover, this efficacy was

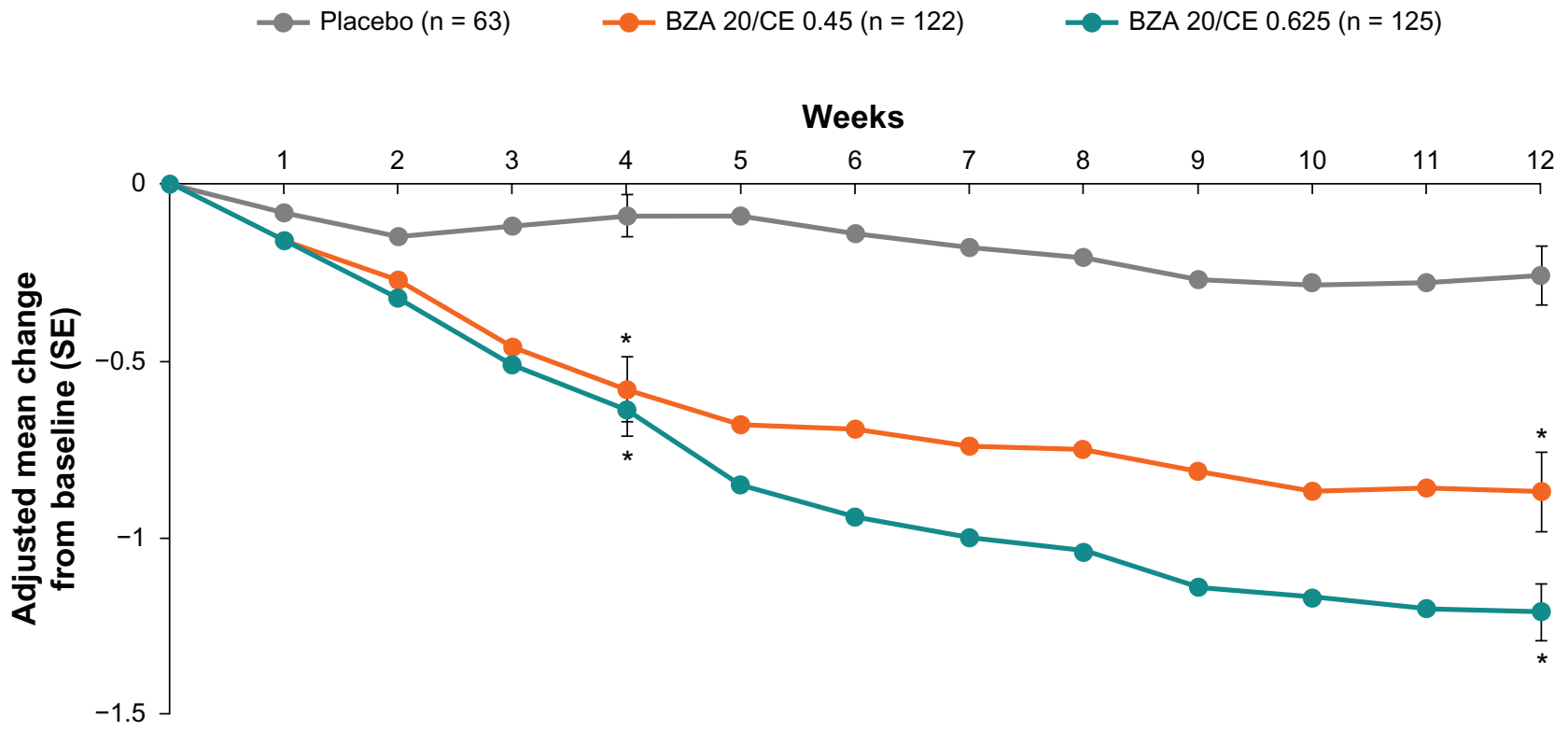

Figure 2 SMART-2 trial: mean daily severity score of hot flushes with up to 12 weeks of treatment with BZA/CE or placebo for the MITT population using LOCF. The mean daily severity score of hot flushes was statistically significant $(P<0.00 I)$ for both BZA/CE doses during weeks 3 through 12 compared with placebo. The mean daily severity score was calculated by summing the number of mild, moderate, and severe hot flushes multiplied by I, 2, and 3, respectively, divided by the total number of hot flushes. *P-value vs placebo $<0.001$.

Abbreviations: BZA, bazedoxifene; CE, conjugated estrogens; LOCF, last observation carried forward; MITT, modified intent-to-treat; SMART, Selective estrogens, Menopause, And Response to Therapy trial; SE, standard error. 
Placebo

BZA 20/CE 0.45

Time to fall asleep

Time slept

Sleep

adequacy

Sleep

disturbance

Somnolence

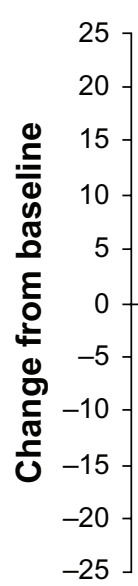

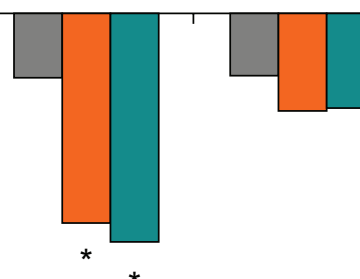

*
Sleep problem index I

Sleep problem

BZA 20/CE 0.625

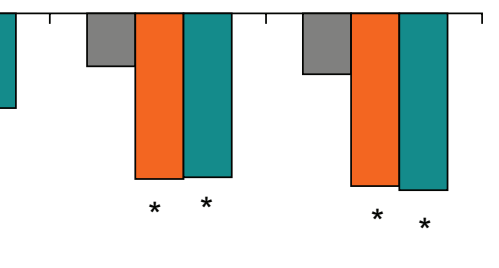

Figure 3 SMART-2 trial: mean change from baseline in the Medical Outcomes Study sleep scale at week I2, MITT population using observed case. BZA/CE improved sleep parameters as measured using this scale. $* P$-value vs placebo $<0.00 \mathrm{I}$; **P-value vs placebo $0.05 \mathrm{I}$; ***P-value vs placebo $0.0 \mathrm{I} 0$.

Abbreviations: BZA, bazedoxifene; CE, conjugated estrogens; SMART, Selective estrogens, Menopause, And Response to Therapy trial; MITT, modified intent-to-treat.

correlated with improvements in sleep and menopauserelated quality of life.

\section{Effects on vulvovaginal atrophy}

Two studies evaluated the efficacy of BZA/CE on vulvovaginal atrophy, ie, SMART-1 and SMART-3. ${ }^{17,19}$ In the SMART-3 trial, the efficacy of BZA $20 \mathrm{mg} / \mathrm{CE} 0.45$ and $0.625 \mathrm{mg}$ on vulvovaginal atrophy was evaluated in subjects who had no more than 5\% superficial cells at screening on the vaginal smear, a vaginal $\mathrm{pH}<5$, and presented with a moderate to severe symptom associated with vulvovaginal atrophy. ${ }^{19}$

BZA $20 \mathrm{mg} / \mathrm{CE} 0.45$ or $0.625 \mathrm{mg}$ showed a significantly greater increase from baseline in the mean proportion of superficial cells compared with placebo $(P<0.001)$. Both BZA/CE groups also showed a significantly greater reduction from baseline in the mean proportion of parabasal cells $(P<0.001)$ and a significantly greater increase from baseline in the mean proportion of intermediate cells $(P<0.05)$ compared with placebo at weeks 4 and 12. Additionally, treatment with BZA $20 \mathrm{mg} / \mathrm{CE} 0.625 \mathrm{mg}$ resulted in a significantly greater decrease from baseline in vaginal $\mathrm{pH}(P<0.001)$ and a greater improvement in the women's most bothersome vulvovaginal atrophy symptoms $(P<0.05)$ compared with placebo (Figure 4). ${ }^{19}$

In SMART-1, BZA/CE showed a similar effect on the vaginal epithelium, inducing a greater increase from baseline in the mean proportion of superficial cells compared with placebo $(P<0.001)$, a greater increase in the mean proportion of intermediate cells $(P<0.001)$, and a greater decrease in the mean proportion of parabasal cells from baseline compared with placebo $(P<0.001)$. This maturation of the vaginal epithelium was associated with a statistically significant reduction in the incidence of dyspareunia relative to placebo during weeks $9-12$ of therapy $(P<0.001)$ and in ease of lubrication score from baseline compared with placebo $(P<0.05)$ on the Arizona Sexual Experiences scale. ${ }^{17,19}$

Additionally, in SMART-3 (subjects with vulvovaginal atrophy), the Menopause-Specific Quality of Life questionnaire results at week 12 showed significant improvements in sexual function and total scores with both $\mathrm{BZA} / \mathrm{CE}$ doses versus placebo or BZA $20 \mathrm{mg}(P<0.001)$. The Menopause Symptoms Treatment Satisfaction Questionnaire results showed that BZA/CE-treated subjects reported significantly greater overall satisfaction with treatment. ${ }^{19}$

\section{Bone effects}

Two clinical trials (SMART-1 and SMART-5) evaluated the safety and efficacy of BZA/CE for the prevention of osteoporosis. ${ }^{17,20}$ Among subjects $\leq 5$ years since menopause (substudy II of SMART-1 and SMART-5), significant $(P<0.001)$ increases from baseline to month 12 in lumbar spine bone mineral density (BMD) were demonstrated for both the BZA $20 \mathrm{mg} / \mathrm{CE} 0.45 \mathrm{mg}(1.05 \%$ and $0.24 \%$ in SMART-1 and SMART-5, respectively) and BZA 
A

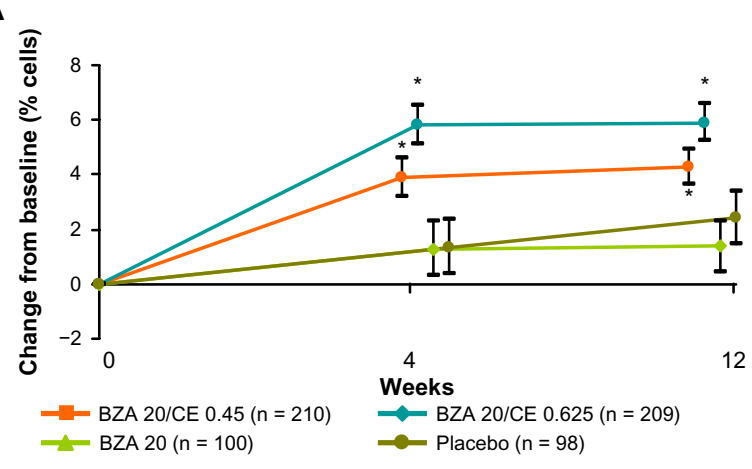

C

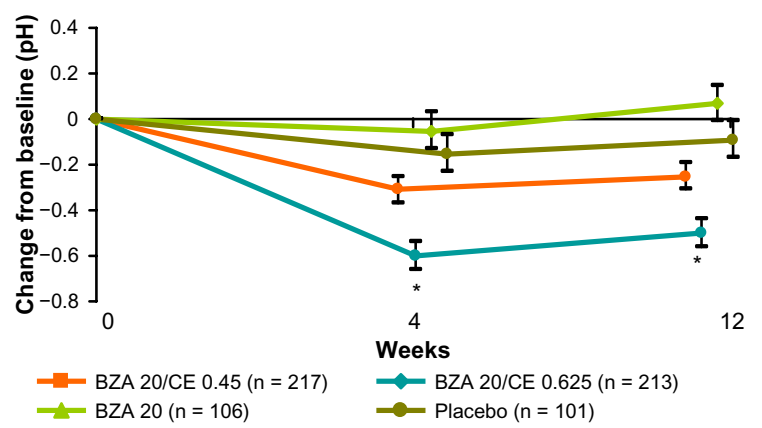

B

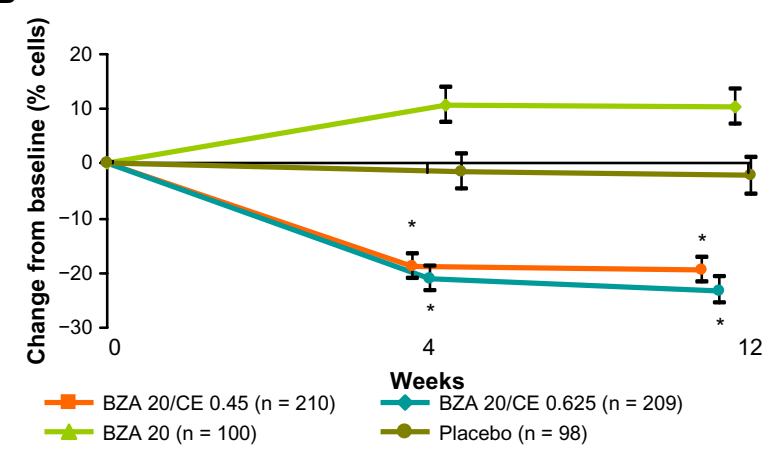

D

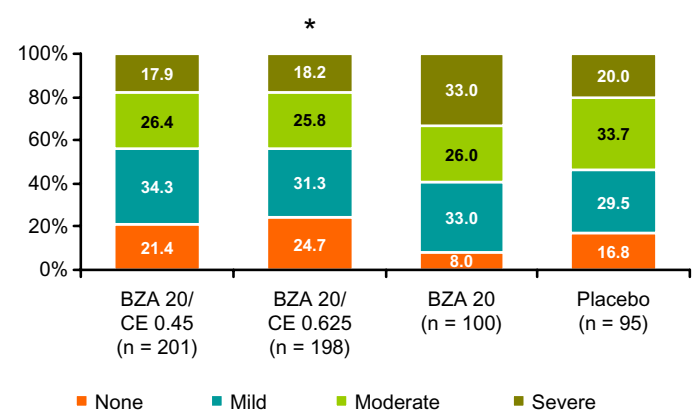

Figure 4 SMART-3 trial: effect of BZA/CE on measurements of vulvovaginal atrophy. (A) Median change from baseline in percentage of vaginal superficial cells at weeks 4 and 12 for treatment with BZA/CE, BZA, or placebo for the MITT population using LOCF. BZA $20 \mathrm{mg} / \mathrm{CE} 0.625 \mathrm{mg}$ and CE $0.45 \mathrm{mg}$ significantly increased superficial cells at week $4(P=0.0034$ and $P<0.00 I)$ and week $12(P<0.00 I$ for both doses $)$ over placebo and BZA using nonparametric analyses. $* P$-value vs placebo $<0.00 \mathrm{I}$. (B) $M$ edian change from baseline in percentage of vaginal parabasal cells at weeks 4 and 12 for treatment with BZA/CE, BZA, or placebo for the MITT population using LOCF. BZA 20 mg/ CE $0.625 \mathrm{mg}$ and CE $0.45 \mathrm{mg}$ significantly decreased superficial cells at week 4 and week $12(P<0.00 \mathrm{I}$ for both doses $)$ over placebo and BZA using nonparametric analyses. $* P$-value vs placebo $<0.001$. (C) Mean change from baseline in vaginal $\mathrm{pH}$ at weeks 4 and 12 for treatment with BZA/CE, BZA, or placebo for the MITT population using LOCF. BZA $20 \mathrm{mg} / \mathrm{CE} 0.625$ but not BZA $20 \mathrm{mg} / \mathrm{CE} 0.45 \mathrm{mg}$ significantly decreased vaginal $\mathrm{pH}$ at week 4 and week I2 $(P<0.00 \mathrm{I})$ over placebo. *P-value vs placebo $<0.00 \mathrm{I}$. (D) Percentage of women with MBS data by severity at week 12. MBS significantly improved with BZA $20 \mathrm{mg} / \mathrm{CE} 0.625 \mathrm{mg}$ compared with placebo and BZA alone at week $12(P<0.05)$. *P-value $=0.048$.

Abbreviations: BZA, bazedoxifene; CE, conjugated estrogens; MBS, most bothersome symptom; SMART, Selective estrogens, Menopause, And Response to Therapy trial; LOCF, last observation carried forward; MITT, modified intent-to-treat.

$20 \mathrm{mg} / \mathrm{CE} 0.625 \mathrm{mg}(1.05 \%$ and $0.60 \%$, in SMART- 1 and SMART-5, respectively) treatment groups compared with placebo $(-1.81 \%$ and $-1.28 \%$, in SMART-1 and SMART-5, respectively)..$^{17,20}$

In addition, in SMART-1, a statistically significant increase in lumbar spine BMD from baseline to month 24 was observed for both the BZA $20 \mathrm{mg} / \mathrm{CE} 0.45 \mathrm{mg}$ and BZA $20 \mathrm{mg} / \mathrm{CE} 0.625 \mathrm{mg}$ treatment groups compared with a decrease in lumbar spine BMD in the placebo group $(P<0.001)$. Raloxifene $60 \mathrm{mg}$ was included as an active comparator in SMART-1; among subjects $\leq 5$ years since menopause, both the BZA $20 \mathrm{mg} / \mathrm{CE} 0.45 \mathrm{mg}$ and BZA $20 \mathrm{mg} / \mathrm{CE} 0.625 \mathrm{mg}$ dose strengths demonstrated a statistically significant greater percentage increase in lumbar spine BMD from baseline to months $12(P<0.001)$ and 24 ( $P=0.002$ and $P=0.001$, respectively) compared with raloxifene $60 \mathrm{mg}$ (Figure 5). ${ }^{17}$ In SMART-5, BZA $20 \mathrm{mg}$ and CE $0.45 \mathrm{mg} / \mathrm{MPA} 1.5 \mathrm{mg}$ were included as active comparators.
BZA/CE (both doses) showed similar efficacy to CE/MPA and a superior bone effect as compared with BZA $20 \mathrm{mg} .{ }^{20}$

SMART-1 and SMART-5 demonstrated that treatment with BZA $20 \mathrm{mg} / \mathrm{CE} 0.45 \mathrm{mg}$ and BZA $20 \mathrm{mg} / \mathrm{CE} 0.625 \mathrm{mg}$ effectively prevented loss of total hip BMD, having a comparable effect to that of raloxifene $60 \mathrm{mg}$ and BZA $20 \mathrm{mg}$ at all time points evaluated. In addition, BZA $20 \mathrm{mg} / \mathrm{CE} 0.45 \mathrm{mg}$ and BZA $20 \mathrm{mg} / \mathrm{CE} 0.625 \mathrm{mg}$ demonstrated a comparable effect to CE $0.45 \mathrm{mg} / \mathrm{MPA} 1.5 \mathrm{mg}$ in terms of effects on BMD at the total hip. ${ }^{17,20}$

The results from subpopulation analyses based on the integrated data from SMART-1 and SMART-5 demonstrate that $\mathrm{BZA} / \mathrm{CE}$ therapy was efficacious regardless of age groups ( $<60$ years versus $\geq 60$ years), BMI, race, and geographic region in improving lumbar spine and total hip BMD. ${ }^{17,20}$

To evaluate further the effect of treatment on bone metabolism, serum samples for determination of osteocalcin, 


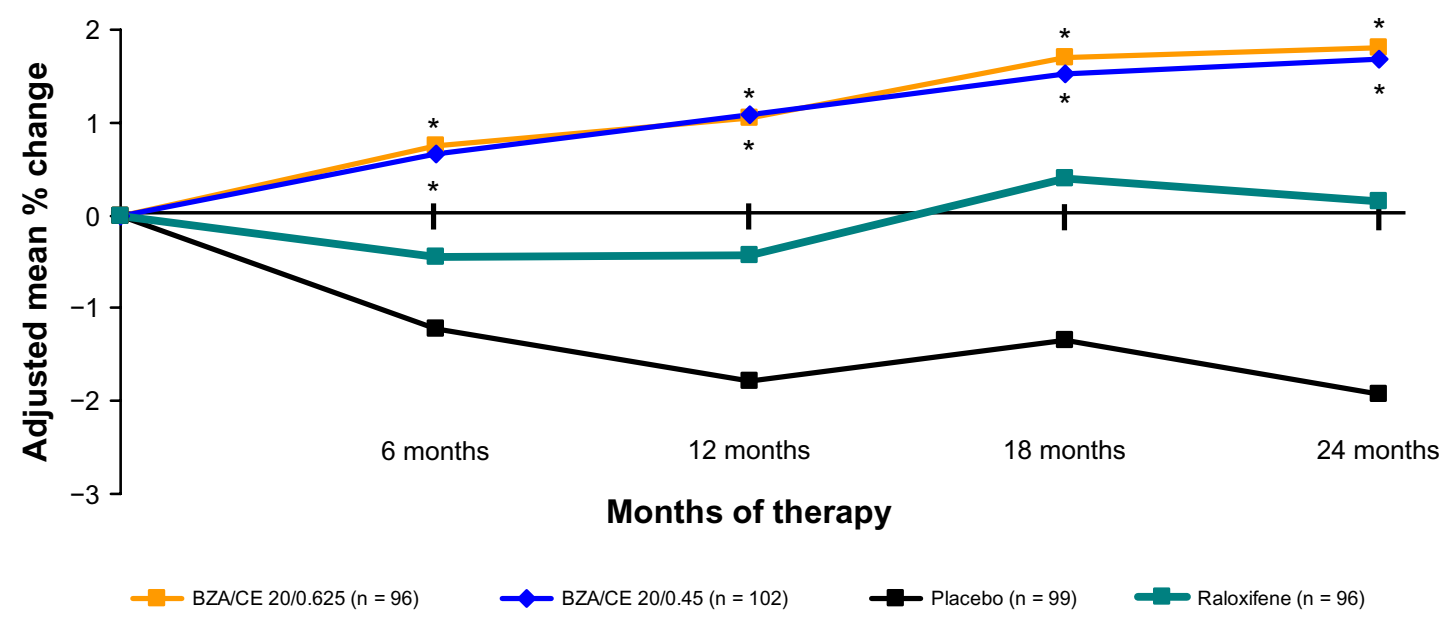

Figure 5 SMART-I trial: Adjusted mean percent change in BMD from baseline to months 6, 12, 18, and 24 from the MITT population using LOCF. BZA/CE increased bone mineral density at the lumbar spine as compared with placebo and baseline values $(P<0.0 \mathrm{I})$ and raloxifene $60 \mathrm{mg}(P<0.05 \mathrm{BZA} / \mathrm{CE})$. $P$-value vs placebo $\leq 0.00 \mathrm{I}$ (all BZA/ CE groups at 6, I2, I8 and $24 \mathrm{~m}$ ); $P$-value versus baseline $\leq 0.00$ I (all BZA/CE groups at $6,12,18$ and $24 \mathrm{~m}$ ); $* P$-value versus RAL $\leq 0.05$ at $6,12,18$ and $24 \mathrm{~m}$.

Abbreviations: BZA, bazedoxifene; CE, conjugated estrogens; SMART, Selective estrogens, Menopause, And Response to Therapy trial; BMD, bone mineral density; MITT, modified intent-to-treat; LOCF, last observation carried forward.

procollagen type $1 \mathrm{~N}$-propeptide (P1NP), and C-telopeptide were obtained in SMART-1 and SMART-5.17,20

The observed decreases in bone turnover markers were consistent with the observed improvements in BMD. Both the BZA $20 \mathrm{mg} / \mathrm{CE} 0.45 \mathrm{mg}$ and BZA $20 \mathrm{mg} / \mathrm{CE} 0.625 \mathrm{mg}$ treatment groups demonstrated significant decreases from baseline in serum concentrations of C-telopeptide and osteocalcin compared with placebo $(P<0.001)$ in SMART-1 and SMART-5. In addition, concentrations of P1NP at months 6 and 12 were significantly decreased $(P<0.001)$ by both doses compared with placebo in SMART-5..$^{17,20}$

A significantly larger decrease $(P<0.001)$ in serum concentrations of C-telopeptide and osteocalcin was observed for both the BZA $20 \mathrm{mg} / \mathrm{CE} 0.45 \mathrm{mg}$ and BZA $20 \mathrm{mg} / \mathrm{CE}$ $0.625 \mathrm{mg}$ treatment groups compared with the raloxifene $60 \mathrm{mg}$ treatment group in SMART-1. ${ }^{17}$

Similarly, in SMART-5, both the BZA $20 \mathrm{mg} / \mathrm{CE}$ $0.45 \mathrm{mg}$ and BZA $20 \mathrm{mg} / \mathrm{CE} 0.625 \mathrm{mg}$ treatment groups demonstrated greater decreases in serum osteocalcin and serum C-telopeptide and significant decreases in P1NP compared with the BZA $20 \mathrm{mg}$ treatment group. Moreover, in SMART-5, both the BZA $20 \mathrm{mg} / \mathrm{CE} 0.45 \mathrm{mg}$ and BZA $20 \mathrm{mg} / \mathrm{CE} 0.625 \mathrm{mg}$ treatment groups demonstrated decreases in P1NP and serum osteocalcin that were comparable with the CE $0.45 \mathrm{mg} / \mathrm{MPA} 1.5 \mathrm{mg}$ treatment group. ${ }^{20}$

Studies conducted with BZA alone provide important supportive evidence for the long-term efficacy (7-year exposure) of BZA in postmenopausal subjects. Treatment with BZA 20 and BZA $40 \mathrm{mg}$ for 3 years resulted in a statistically significant reduction $(P<0.05)$ in the incidence of new vertebral fractures compared with placebo which was similar to that observed with raloxifene $60 \mathrm{mg}$. This positive effect in reduction of new vertebral fractures was observed through 5 and 7 years of treatment. ${ }^{23}$

Overall, the skeletal effects (changes in lumbar spine and hip BMD and bone turnover markers) observed with $\mathrm{BZA} / \mathrm{CE}$ therapy were clinically meaningful and greater than for raloxifene and BZA monotherapy and comparable with CE $0.45 \mathrm{mg} / \mathrm{MPA} 1.5 \mathrm{mg}$. The increases in BMD and decrease in bone turnover markers observed with BZA/ $\mathrm{CE}$ as compared with placebo have been associated with a reduction in fracture risk with antiresorptive agents as well as with BZA treatment.

\section{Safety Endometrial safety}

Protection of the endometrium is of major clinical importance for non-hysterectomized postmenopausal women who receive a therapy containing estrogens. Therefore, the tissue selective activity of the selective estrogen receptor modulator component of $\mathrm{BZA} / \mathrm{CE}$ is key to endometrial protection. ${ }^{16}$ The incidence of endometrial hyperplasia with BZA/CE was evaluated in SMART-1 and SMART-5. These studies were of sufficient duration to provide evidence that BZA $20 \mathrm{mg} / \mathrm{CE}$ $0.45 \mathrm{mg}$ and BZA $20 \mathrm{mg} / \mathrm{CE} 0.625 \mathrm{mg}$ provides appropriate endometrial protection. Both doses of BZA/CE demonstrated an incidence of endometrial hyperplasia $<1 \%$, which was comparable with placebo. ${ }^{17,24}$

Data obtained using transvaginal ultrasound have also shown neutral effects of BZA/CE on the endometrium. $\mathrm{BZA} / \mathrm{CE}$ were associated with minimal increases in endometrial thickness from baseline $(<1 \mathrm{~mm})$ which were 
similar to placebo. ${ }^{20}$ More subjects treated with CE/MPA in the SMART-5 trial had an increase in endometrial thickness of $>5 \mathrm{~mm}$ compared with $\mathrm{BZA} / \mathrm{CE}$ or placebo. ${ }^{20}$

The effects of BZA/CE on endometrial bleeding have also been evaluated in the SMART trials. ${ }^{20,25}$ In SMART-1 and SMART-5, BZA $20 \mathrm{mg} / \mathrm{CE} 0.45$ and $0.625 \mathrm{mg}$ were associated with high rates of cumulative amenorrhea, similar to placebo. The rates of cumulative amenorrhea over one year were $>83 \%,>87 \%$, and $>85 \%$ for BZA $20 \mathrm{mg} / \mathrm{CE} 0.45 \mathrm{mg}$, BZA $20 \mathrm{mg} / \mathrm{CE} 0.625 \mathrm{mg}$, and placebo, respectively, in SMART-1. ${ }^{25}$ Higher rates of cumulative amenorrhea were observed with BZA $20 \mathrm{mg} / \mathrm{CE} 0.45$ and $0.625 \mathrm{mg}$ (>87\% and $>84 \%$, respectively) and placebo $(>83 \%)$ compared with CE/MPA $(>54 \%)$ in SMART-5 (Figure 6). ${ }^{20}$

\section{Breast safety}

The effect of BZA/CE regimens on the incidence of breast pain/tenderness was evaluated in SMART-1, SMART-2, and SMART-5. ${ }^{17,18,20}$ In these studies, breast pain/tenderness was measured by daily subject diaries. Both the BZA $20 \mathrm{mg} / \mathrm{CE}$ $0.45 \mathrm{mg}$ and BZA $20 \mathrm{mg} / \mathrm{CE} 0.625 \mathrm{mg}$ dose strengths demonstrated an incidence of breast pain/tenderness that was not significantly different compared with placebo, raloxifene $60 \mathrm{mg}$, and BZA $20 \mathrm{mg} .{ }^{17}$ In SMART-5, the incidence of breast tenderness in subjects treated with BZA/CE was significantly lower than that in subjects treated with $\mathrm{CE}$ $0.45 \mathrm{mg} / \mathrm{MPA} 1.5 \mathrm{mg}(P<0.001$, Figure 7$) .{ }^{20}$ These results are consistent with the relative incidences of adverse events related to breast pain/tenderness and discontinuation rates due to breast pain/tenderness reported by participants in the SMART trials. ${ }^{17-20}$

In SMART-5, both the BZA $20 \mathrm{mg} / \mathrm{CE} 0.45 \mathrm{mg}$ and BZA $20 \mathrm{mg} / \mathrm{CE} 0.625 \mathrm{mg}$ treatment groups demonstrated non-inferiority compared with placebo with regards to mammographic breast density. By contrast, the CE $0.45 \mathrm{mg} / \mathrm{MPA}$ $1.5 \mathrm{mg}$ treatment group exhibited a significant increase in breast density compared with the placebo group. BZA/ $\mathrm{CE}$ treatment did not affect age-related changes in mammographic breast density (ie, natural reduction in breast density throughout the years of menopause). The results demonstrated that, unlike estrogen progestin-containing HT, BZA $20 \mathrm{mg} / \mathrm{CE} 0.45 \mathrm{mg}$, and BZA $20 \mathrm{mg} / \mathrm{CE} 0.625 \mathrm{mg}$ have a neutral (similar to placebo) effect on breast density. ${ }^{20}$

\section{General safety}

Based on the integrated safety results of the SMART trials, the BZA $20 \mathrm{mg} / \mathrm{CE} 0.45 \mathrm{mg}$ and BZA $20 \mathrm{mg} / \mathrm{CE} 0.625 \mathrm{mg}$ dose strengths are well tolerated and have an acceptable safety profile, supporting use in generally healthy, postmenopausal women with a uterus. ${ }^{17-20}$

The incidences of treatment-emergent adverse events, serious adverse events, and discontinuations due to adverse events were similar among the treatment groups. The incidence of venous thromboembolism was low, as expected in

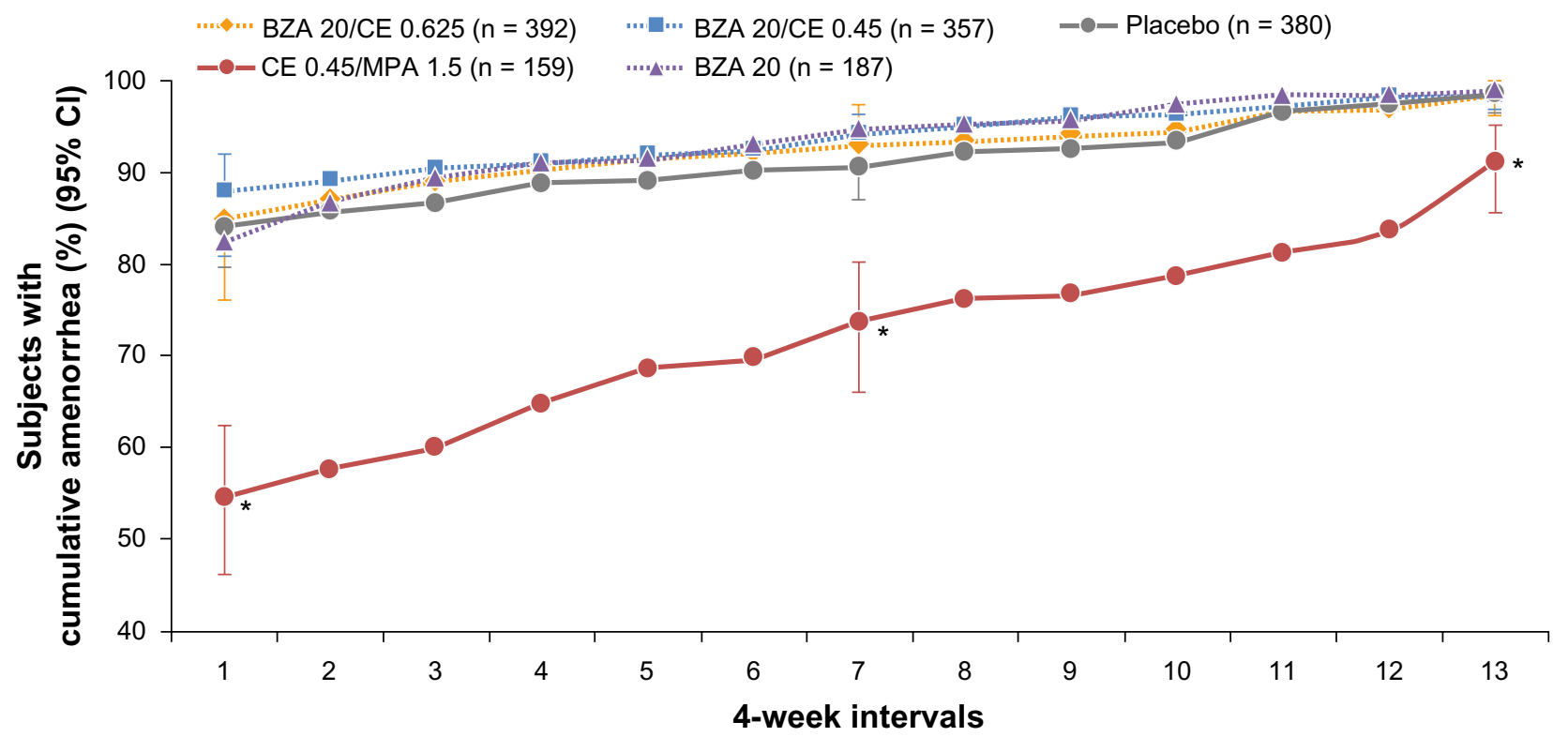

Figure 6 SMART-5 trial: Percentage (standard error) of subjects with amenorrhea during cycles I-I3 (MITT population) for each treatment group. BZA/CE (both doses), $B Z A$, and placebo demonstrated a similar incidence of cumulative amenorrhea for all cycles. CE/MPA showed a significantly lower amenorrhea rate $(P<0.00 \mathrm{I}$ versus all other treatment groups). No difference between any Bazedoxifene/CE group and placebo. $* P<0.00 \mathrm{I}$ vs placebo.

Abbreviations: BZA, bazedoxifene; CE, conjugated estrogens; MPA, medroxyprogesterone acetate; SMART, Selective estrogens, Menopause, And Response to Therapy trial; $\mathrm{Cl}$, confidence interval; MITT, modified intent-to-treat. 


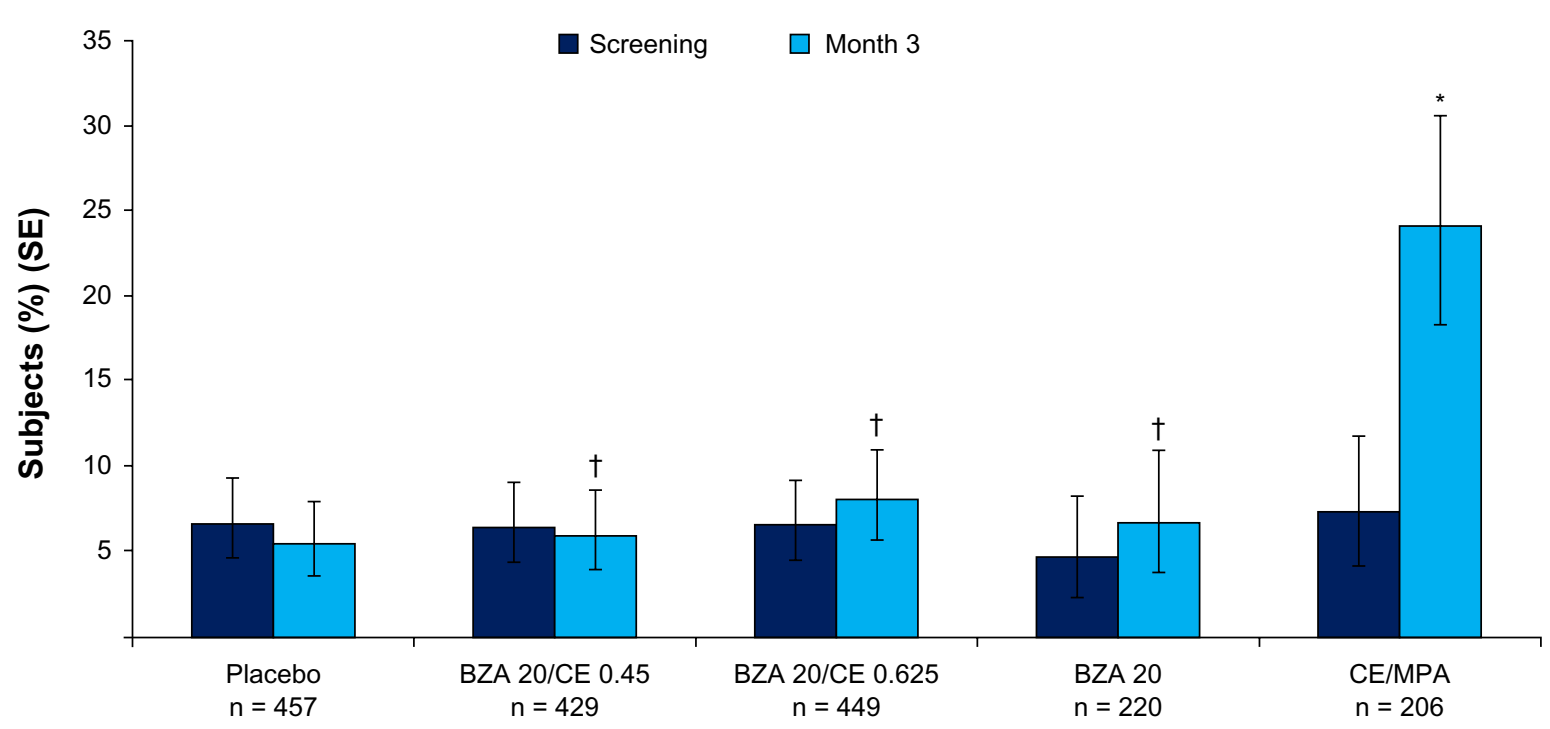

Figure 7 Percentage of women reporting one or more days of breast tenderness at week I2. BZA/CE (both doses), BZA, and placebo demonstrated similar incidences of breast tenderness. CE/MPA showed a significantly higher rates $\left(P<0.001\right.$ versus all other treatment groups). $* P<0.00$ I vs placebo; ${ }^{\dagger} P<0.00 \mathrm{I}$ vs $C E / M P A$. No difference between any Bazedoxifene/CE group and placebo at 9-12 wks.

Abbreviations: BZA, bazedoxifene; CE, conjugated estrogens; MPA, medroxyprogesterone acetate.

this relatively healthy population and consistent with what was reported in the Women's Health Initiative study. ${ }^{26}$ The risk does not appear to be any greater than for $\mathrm{CE}$ alone or BZA alone or greater than for CE/MPA. ${ }^{26,27}$ The incidences of coronary heart disease and cerebrovascular accidents were similar to those on placebo. The incidence of estrogensensitive cancers, including breast cancer, endometrial cancer, and ovarian cancer, was low and similar to placebo.

Clinical laboratory tests demonstrated that the BZA $20 \mathrm{mg} / \mathrm{CE} 0.45 \mathrm{mg}$ and BZA $20 \mathrm{mg} / \mathrm{CE} 0.625 \mathrm{mg}$ doses were associated with a favorable lipid profile (decreases in total cholesterol, low-density lipoprotein, increases in high-density lipoprotein) with the exception of an increase in triglyceride levels. ${ }^{20}$ Both the BZA $20 \mathrm{mg} / \mathrm{CE} 0.45 \mathrm{mg}$ and BZA $20 \mathrm{mg} / \mathrm{CE} 0.625 \mathrm{mg}$ dose strengths were associated with an increase from baseline in serum triglycerides which was similar to that reported for estrogen progestincontaining $\mathrm{HT}^{28}$ No other clinically significant changes in clinical laboratory tests were noted.

There were no significant differences in the adjusted mean change in body weight with either BZA/CE dose compared with placebo at one year or at the final on-therapy evaluation; this was the case among subjects in the overall population as well as in the two subgroups of women with a BMI $<25 \mathrm{~kg} / \mathrm{m}^{2}$ or $\geq 25 \mathrm{~kg} / \mathrm{m}^{2}$. The percentages of subjects with body weight changes of potential clinical importance (an increase or decrease from baseline of $\geq 15 \%$ or $\geq 11 \mathrm{~kg}$ ) were low and not significantly different between the $\mathrm{BZA} / \mathrm{CE}$ and placebo groups in the overall population or in the two subgroups of women with a BMI $<25 \mathrm{~kg} / \mathrm{m}^{2}$ or $\geq 25 \mathrm{~kg} / \mathrm{m}^{2} .{ }^{17-20}$

Changes from baseline in mean systolic blood pressure were less than $2.00 \mathrm{mmHg}$ in the BZA $20 \mathrm{mg} / \mathrm{CE} 0.45 \mathrm{mg}$ group and BZA $20 \mathrm{mg} / \mathrm{CE} 0.625 \mathrm{mg}$ group; these changes were similar to those observed for the placebo group. The mean change in systolic blood pressure was comparable with that seen on placebo at all time points evaluated. ${ }^{17-20}$

\section{Conclusion}

Treatment with BZA/CE demonstrated clinically meaningful improvements in vasomotor symptoms and vulvovaginal atrophy as well as a protective effect on the skeleton in postmenopausal women seeking treatment for menopausal symptoms, while protecting the endometrium. BZA/CE also showed significant improvements in tolerability compared with HT, as measured by lower rates of uterine bleeding and breast pain. BZA/CE treatment had an effect on breast density similar to placebo. These clinical benefits were associated with an acceptable safety profile. No apparent increased risk for serious adverse events, such as venous thromboembolism, cardiovascular events, endometrial cancer, or breast cancer, was observed with either dose strength of BZA/CE. BZA/ $\mathrm{CE}$ is an alternative option for treating non-hysterectomized, symptomatic postmenopausal women.

\section{Disclosure}

SM is an employee of Pfizer Inc. JHP was formerly an employee of Wyeth Research, and has consulted 
for Wyeth/Pfizer, Depomed, BHR Pharma, ASCEND Therapeutics, TherapeuticsMD, Ausio Pharmaceuticals, and Shionogi.

\section{References}

1. Archer DF. Tissue-selective estrogen complexes: a promising option for the comprehensive management of menopausal symptoms. Drugs Aging. 2010;27:533-544.

2. Maartens LW, Leusink GL, Knottnerus JA, et al. Climacteric complaints in the community. Fam Pract. 2001;18:189-194.

3. Lewis V. Undertreatment of menopausal symptoms and novel options for comprehensive management. Curr Med Res Opin. 2009;25: 2689-2698.

4. Geukes M, van Aalst MP, Nauta MCE, et al. The impact of menopausal symptoms on work ability. Menopause. 2012;19:278-282.

5. Gold EB, Sternfeld B, Kelsey JL, et al. Relation of demographic and lifestyle factors to symptoms in a multi-racial/ethnic population of women 40-55 years of age. Am J Epidemiol. 2000;152:463-473.

6. Dennerstein L, Dudley EC, Hopper JL, et al. A prospective populationbased study of menopausal symptoms. Obstet Gynecol. 2000;96: 351-358.

7. Al-Azzawi F, Habiba M. Regular bleeding on hormone replacement therapy: a myth? Br J Obstet Gynaecol. 1994;101:661-662.

8. Limouzin-Lamothe MA. What women want from hormone replacement therapy: results of an international survey. Eur J Obstet Gynecol Reprod Biol. 1996;64 Suppl:S21-S24.

9. Pfizer Pharmaceuticals Inc. PremPro package insert. Available from: http://labeling.pfizer.com/showlabeling.aspx?id=133. Accessed October 11, 2011.

10. Persson I, Thurfjell E, Holmberg L. Effect of estrogen and estrogenprogestin replacement regimens on mammographic breast parenchymal density. J Clin Oncol. 1997;15:3201-3207.

11. Lee E, Ingles SA, Berg VD, et al. Progestogen levels, progesterone receptor gene polymorphisms, and mammographic density changes: results from the Postmenopausal Estrogen/Progestin Interventions Mammographic Density Study. Menopause. 2012;19:302-310.

12. Brower V. Homing in on mechanisms linking breast density to breast cancer risk. J Natl Cancer Inst. 2010;102:843-845.

13. Kerlikowske K, Cook AJ, Buist DSM. Breast cancer risk by breast density, menopause, and postmenopausal hormone therapy use. J Clin Oncol. 2010;28:3830-3837.

14. Crandall CJ, Aragaki AK, Cauley JA, et al. Breast tenderness and breast cancer risk in the estrogen plus progestin and estrogen-alone women's health initiative clinical trials. Breast Cancer Res Treat. 2012; 132:275-285.
15. Haas JS, Kaplan CP, Gerstenberger EP, Kerlikowske K. Changes in the use of postmenopausal hormone therapy after the publication of clinical trial results. Ann Intern Med. 2004;140:184-188.

16. Komm B. A new approach to menopausal therapy: the tissue selective estrogen complex. Reprod Sci. 2008;15:984-992.

17. Lobo RA, Pinkerton JV, Gass ML, et al. Evaluation of bazedoxifene/ conjugated estrogens for the treatment of menopausal symptoms and effects on metabolic parameters and overall safety profile. Fertil Steril. 2009;92:1025-1038.

18. Pinkerton JV, Utian WH, Constantine GD, Olivier S, Pickar JH. Relief of vasomotor symptoms with the tissue-selective estrogen complex containing bazedoxifene/conjugated estrogens: a randomized, controlled trial. Menopause. 2009;16:1116-1124.

19. Kagan R, Williams RS, Pan K, Mirkin S, Pickar JH. A randomized, placebo- and active-controlled trial of bazedoxifene/conjugated estrogens for treatment of moderate to severe vulvar/vaginal atrophy in postmenopausal women. Menopause. 2010;17:281-289.

20. Pinkerton JV, Taylor H, Pan K, Chines A, Mirkin S. Breast parameters with bazedoxifene/conjugated estrogens in randomized, controlled trials of postmenopausal women. Menopause. 2010;17:1221-1222.

21. MacLennan AH, Broadbent JL, Lester S, Moore V. Oral oestrogen and combined oestrogen/progestogen therapy versus placebo for hot flushes. Cochrane Database Syst Rev. 2004;4:CD002978.

22. Utian W, Yu H, Bobula J, Mirkin S, Olivier S, Pickar JH. Bazedoxifene/ conjugated estrogens and quality of life in postmenopausal women. Maturitas. 2009;63:329-335.

23. de Villiers TJ. Bazedoxifene: a novel selective estrogen receptor modulator for postmenopausal osteoporosis. Climacteric. 2010;13:210-218.

24. Pickar JH, Yeh I-T, Bachmann G, Speroff L. Endometrial effects of a tissue selective estrogen complex containing bazedoxifene/ conjugated estrogens as a menopausal therapy. Fertil Steril. 2009;92: 1018-1024.

25. Archer DF, Lewis V, Carr BR, Olivier S, Pickar JH. Bazedoxifene/ conjugated estrogens (BZA/CE): incidence of uterine bleeding in postmenopausal women. Fertil Steril. 2009;92:1039-1044.

26. Chlebowski RT, Hendrix SL, Langer RD, et al. Influence of estrogen plus progestin on breast cancer and mammography in healthy postmenopausal women. JAMA. 2003;289:3234-3253.

27. Pfizer Pharmaceuticals Inc. Premarin US Package Insert. Available from: http://labeling.pfizer.com/showlabeling.aspx?id=131. Accessed December 13, 2011.

28. Lobo RA, Bush T, Carr BR, Pickar JH. Effects of lower doses of conjugated equine estrogens and medroxyprogesterone acetate on plasma lipids and lipoproteins, coagulation factors, and carbohydrate metabolism. Fertil Steril. 2001;76:13-24.
International Journal of Women's Health

\section{Publish your work in this journal}

The International Journal of Women's Health is an international, peerreviewed open-access journal publishing original research, reports, editorials, reviews and commentaries on all aspects of women's healthcare including gynecology, obstetrics, and breast cancer. The manuscript management system is completely online and includes

\section{Dovepress}

a very quick and fair peer-review system, which is all easy to use. Visit http://www.dovepress.com/testimonials.php to read real quotes from published authors. 